\title{
How a graduate school education can meet the needs of industrial employment
}

Published online: 6 June 2002

(C) Springer-Verlag 2002

Three major areas of employment exist for advanced degree analytical chemists. Academia, governmental laboratories, and industrial laboratories all draw from graduate schools to meet manpower requirements. However, the skill set required to successfully function in each of these three working environments is rather different. By its inherent nature, a traditional graduate school education is geared heavily towards preparing an individual for an academic career. Academicians know best how to train those aiming for similar careers. Employment in a government laboratory will not be covered in this discussion, but may be in the future by someone from that area.

Industrial analytical chemists work under very different premises than academicians. The scientific areas to be studied in academia are typically defined by the granting organizations that provide research funding and the interests of the research professors. Funding is often done over timeframes of two, three, or more years and the goals are often more in the nature of gaining knowledge for its own sake. The working group for a particular project is often limited in size, consisting of the research professor and a very small number of graduate and post-doctoral students.

In industry, projects are defined by outside factors well beyond the control of the individual scientist. The driving force for a particular project varies widely, ranging over such areas as analytical methodology for use in monitoring the purity of a new product, to solving an immediate need produced by failed product specifications or equipment problems, or to a host of other (most often economic) reasons. The timeframes for projects are seldom more than a year in length and are often only days or weeks long.

How can a graduate school environment provide a development opportunity for timeframe skills such as these? If academic projects are large and very long-term, there is still ample opportunity to, at times, segment work so that there are shorter-term goals to be met. Planning these and

J.C. Fetzer (로)

1283 Santa Fe, Hercules CA 94547-3707 USA

e-mail: Fetzerhaus@sprintmail.com integrating them back into the total project will hone timeframe skills that prove very useful when applied to the shorter-term focus of industrial work.

The industrial scientist is often the only technical leader in a particular area of expertise. This is in contrast to graduate school where this role is held by the research advisory professor. In academia, there are variations on this which often depend on the level of the professor. For beginning professors, focused on building a reputation and attaining tenure, the graduate students are co-workers with the professor being both an active researcher and playing the leading role in the team. For more senior professors, the role is as a research advisor, funding raiser, and mentor, often with senior graduate or post-doctoral students providing the in-laboratory leadership.

What can graduate schools do to prepare the industrial analytical chemist for technical autonomy and authority? An emphasis on being part of the planning and decision making on research projects, even if only for portions of the overall project, gives the student experience in this area. As the student develops, the reliance on other more senior members of the research group to do this must decrease, with the student growing into a leadership role that involves planning, feasibility estimates, and budgets. In an industrial setting it will be expected that the analytical chemist contribute estimates of funding levels and schedules needed to accomplish the analytical work.

In industry, the research teams dealing with a particular project can (and usually do) include many people trained in other scientific and engineering disciplines, such as organic chemists, materials scientists, and chemical engineers. Each project or problem to be solved has an individual mix of people, each focused on an area of expertise and adding to the overall progress of the team. Diversity of knowledge becomes an inherent part of all analytical work since the other collaborators generally do not know nor are expected to know what analytical approaches are best.

In this electronic age, real team meetings are not as necessary as in the past. Writing skills are needed to create clear and concise work plans and pass on ideas. Speaking skills are still needed as well, as there are often updates 
and reviews required for the various other team members as well as management updates. Teamwork and communication skills are definitely strong needs, but balanced with the ability to work autonomously on one's own specific tasks.

How can these skills be learned in the graduate school educational environment? One answer is to create an atmosphere where collaboration is important. Too often in academia, each research project progresses in isolation, with no involvement by anyone outside of the research group. Another solution is a more synergistic approach to the research project, where a student relies on more than just the research advisor and others from the research group for ideas. Relying on others outside of the research group or outside of the specific department or even the particular university, builds the collaborative attitudes and communications skills that are invaluable later in the industrial lab setting.

The analytical chemist is responsible for both the specific analytical issues surrounding a project, as well as how the proposed solution will mesh with other, often nontechnical, factors. For example, a chemical plant cannot often use complex, sophisticated analysis methods because the personnel who would be required to run the method at the plant cannot maintain the equipment adequately nor have the experience to run the equipment effectively. On the other hand, problem solving often utilizes very complex analytical solutions. The range of knowledge of the industrial analytical chemist must be much wider than the academic counterpart, but the requirement for depth of knowledge is not as great. A successful academician is expected to be an expert, even if only in a narrowly defined topic; the industrial chemist must have some working knowledge in a multitude of areas. This has become particularly acute in this era of "bottom-line accounting" and "downsizing" due to mergers and acquisitions. Staffing levels are much leaner than in the past. Companies rely on a few, talented individuals to do much more. (As a corollary to this area, companies no longer "hire for life". Mergers and acquisitions usually lead to job cuts that increase the need for analytical chemists to be flexible just in case a career move is either chosen by or forced upon in today's disruptive, dynamic business environment.).

How can skills needed to address these issues be developed in graduate school? Besides the knowledge gained through more collaboration, students can develop some understanding of a wider range of topics if that is structured into their educational requirements. Requiring course work is a common solution in graduate schools, but this should not be viewed as the sole solution. A good graduate program creates the habit of reading journals and books on a wider variety of topics than only the ones involved in the graduate student's research. The industrial analytical chemist often has to draw on knowledge outside of his or her core area of expertise. A chromatographer, for example, may need to be versed in molecular spectroscopy or organic syntheses in order to apply the best solution to a problem. In many industrial labs there are no experts in all areas of analytical chemistry, so a person can branch out into a variety of areas because of needs.

The differences between an industrial position and an academic one require that a graduate school educator teaches versatility, teamwork, and a shorter-term more applied focus to the work. There are similarities, though, in requiring creativity, good communications skills, and a thorough knowledge of one's field.

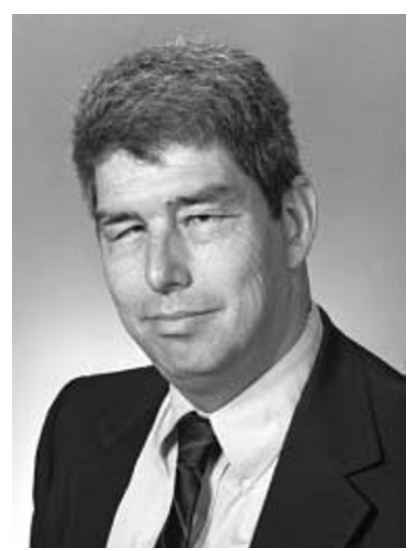

Dr. Fetzer received a $\mathrm{PhD}$ from the University of Georgia, where he studied under Dr. L. B. Rogers. $\mathrm{He}$ is the author or co-author of over 130 research articles, reviews, and book chapters. He is the author of The Chemistry and Analysis of the Large Polycyclic Aromatic Hydrocarbons (John Wiley, 2000). He worked for over 20 years as an analytical chemist for Chevron Corporation and now runs his own consulting company, Fetzpahs Consulting, in Hercules, California, USA. 